\title{
Additive Manufacturing of Titanium with Different Surface Structures for Adhesive Bonding and Thermal Direct Joining with Fiber-Reinforced Polyether-Ether-Ketone (PEEK) for Lightweight Design Applications
}

\author{
Juliane Moritz ${ }^{1,2, *}$, Philipp Götze ${ }^{2}$, Tom Schiefer ${ }^{2}$, Lukas Stepien ${ }^{2}$, Annett Klotzbach ${ }^{2}$, Jens Standfuß ${ }^{2}$, \\ Elena López ${ }^{2}$, Frank Brückner ${ }^{2,3}$ and Christoph Leyens ${ }^{1,2}$ \\ 1 Institute of Materials Science (IfWW), Technische Universität Dresden, Helmholtzstr. \\ 7, 01069 Dresden, Germany; christoph.leyens@iws.fraunhofer.de \\ 2 Fraunhofer Institute for Material and Beam Technology IWS, Winterbergstraße 28, 01277 Dresden, Germany; \\ philipp.goetze@iws.fraunhofer.de (P.G.); tom.schiefer@iws.fraunhofer.de (T.S.); \\ lukas.stepien@iws.frauhofer.de (L.S.); annett.klotzbach@iws.fraunhofer.de (A.K.); \\ jens.standfuss@iws.fraunhofer.de (J.S.); elena.lopez@iws.fraunhofer.de (E.L.); \\ frank.brueckner@iws.fraunhofer.de (F.B.) \\ 3 Department of Engineering Sciences and Mathematics, Luleå University of Technology, 97187 Luleå, Sweden \\ * Correspondence: juliane.moritz@iws.fraunhofer.de; Tel.: +49-351-83391-3878
}

Citation: Moritz, J.; Götze, P.; Schiefer, T.; Stepien, L.; Klotzbach, A.; Standfuß, J.; López, E.; Brückner, F.; Leyens, C. Additive Manufacturing of Titanium with Different Surface Structures for Adhesive Bonding and Thermal Direct Joining with Fiber-Reinforced Polyether-Ether-Ketone (PEEK) for Lightweight Design Applications. Metals 2021, 11, 265. https:// doi.org/10.3390/met11020265

Academic Editor: Joachim Hausmann Received: 20 December 2020

Accepted: 29 January 2021

Published: 4 February 2021

Publisher's Note: MDPI stays neutral with regard to jurisdictional claims in published maps and institutional affiliations.

Copyright: (c) 2021 by the authors. Licensee MDPI, Basel, Switzerland. This article is an open access article distributed under the terms and conditions of the Creative Commons Attribution (CC BY) license (https:// creativecommons.org/licenses/by/ $4.0 /)$.

\begin{abstract}
Hybrid joints consisting of metals and fiber-reinforced polymer composites exhibit highly desirable properties for many lightweight design applications. This study investigates the potential of additively manufactured surface structures for enhancing the bond strength of such joints in comparison to face milled and laser structured surfaces. Titanium samples with different surface structures (as-built surface, groove-, and pin-shaped structures) were manufactured via electron beam melting and joined to carbon fiber-reinforced polyether-ether-ketone (PEEK) via adhesive bonding and thermal direct joining, respectively. Bond strength was evaluated by tensile shear testing. Samples were exposed to salt spray testing for $1000 \mathrm{~h}$ for studying bond stability under harsh environmental conditions. The initial tensile shear strengths of the additively manufactured samples were competitive to or in some cases even exceeded the values achieved with laser surface structuring for both investigated joining methods. The most promising results were found for pin-shaped surface structures. However, the hybrid joints with additively manufactured structures tended to be more susceptible to degradation during salt spray exposure. It is concluded that additively manufactured structures can be a viable alternative to laser surface structuring for both adhesive bonding and thermal direct joining of metal-polymer hybrid joints, thus opening up new potentials in lightweight design.
\end{abstract}

Keywords: metal-polymer hybrid joints; thermal direct joining; adhesive bonding; additive manufacturing; titanium; carbon fiber-reinforced PEEK; laser surface structuring; salt spray testing

\section{Introduction}

Due to the growing demand to lower the consumption of fossil fuels and to reduce greenhouse gas emissions, lightweight design has become increasingly important. This holds particularly true for the transportation sector [1]. Even though polymers can be used to reduce structural weight due to their low density, their mechanical properties often do not meet the requirements regarding strength and stiffness of structural components. These limitations can be overcome by using composite materials, such as carbon fiber-reinforced polymers (CFRP). In aviation, composite materials have exhibited an upward trend over recent decades and account for approximately $50 \%$ of the materials used in the novel aircraft types Boeing 787 and Airbus A350 [2,3]. Lightweight design applications can even 
be advanced further by utilizing fiber metal laminates consisting of alternating layers of metal and fiber-reinforced polymer composites. These hybrid structures combine the superior fracture toughness of the composite component with the high impact resistance of the metal part, which makes them especially interesting for automotive and aerospace applications [4,5]. Exemplary applications in automotive construction are front-end carriers or brake pedals [6]. An example for the use of hybrid structures in aircraft production is the upper fuselage section of the Airbus A380, which is $25 \%$ lighter than a conventional structure [4].

Nowadays, the most common methods for joining metals and polymers include screwing, riveting, injection over-molding, and adhesive bonding. However, the use of screws, bolts, and rivets leads to uneven load distributions [7] and high local stress concentrations, which may have an impact on service reliability of those joints [8]. Moreover, these mechanical fasteners require the drilling of through-holes, which cut through the reinforcing fibers of the composite and impair the structural integrity and mechanical properties of the component [9-11]. Last but not least, mechanical fasteners can significantly contribute to the overall component weight, thus contradicting the principles of lightweight design [10].

During the injection over-molding process, the metal part is placed in a tool for injection molding and is surrounded by the polymer melt, resulting in a positive locking upon solidification. A surface treatment often is necessary prior to injection molding in order to ensure sufficient bond strength, which can significantly increase cycle times [6].

Adhesive bonding has become established in many high-performance applications, since it does not weaken the single components of the joint and provides a simple yet effective solution for joining large areas of different materials, thus overcoming some of the main issues observed with mechanical fasteners [12].

In addition to those well-established joining techniques, thermal joining processes, e.g., based on laser radiation or inductive heating, can be used to form polymer-metal hybrid structures. The polymer is plasticized or partly melted due to the heat input and wets the metal surface. Upon solidification, a firm bond is created between both components [6,12]. In this study, thermal direct joining based on inductive heating was applied, which is well suited to joining metals and fiber-reinforced polymers due to the rapid heating [13]. The short process times result in a high economic efficiency of the technology [14-16]. The general principle of the process is illustrated in Figure 1.

The two components are brought together at the envisaged joining zone. In order to improve heat transfer and wetting, the whole process is conducted under a constant joining pressure. By applying a high-frequency alternating voltage, an alternating electromagnetic field is induced in the metal part. Heat is generated as a consequence of eddy current losses. The polymer is melted at the interface due to heat conduction [12,13]. The bond between both joint partners is established both by micro-mechanical interlocking and by chemical and physical adhesion forces as the polymer is reconsolidated [6].

Several studies have investigated the joining of polyether-ether-ketone (PEEK) and titanium parts, mainly for applications in aviation or biomedicine [17-19]. The adhesion and failure mechanisms in titanium/carbon fiber-reinforced PEEK laminates were studied by Schulze et al., who found that laser surface structuring of the metal counterpart could substantially improve bond strength and stability under hydrothermal conditions due to micro-mechanical interlocking [17]. Henriques et al. compared the effect of grit blasting and laser surface structuring of titanium Ti-6Al-4V samples on the adhesion of titanium/PEEK joints and reported a significant improvement in bond strength for the laser structured specimens [18]. Cortes et al. investigated the mechanical properties of carbon fiberreinforced PEEK/titanium fiber metal laminates. The laminates had been fabricated by means of heating and subsequent stamping of alternating layers of metal and composite sheets, using a PEEK hot-melt as an interlayer to ensure good bonding [19]. 


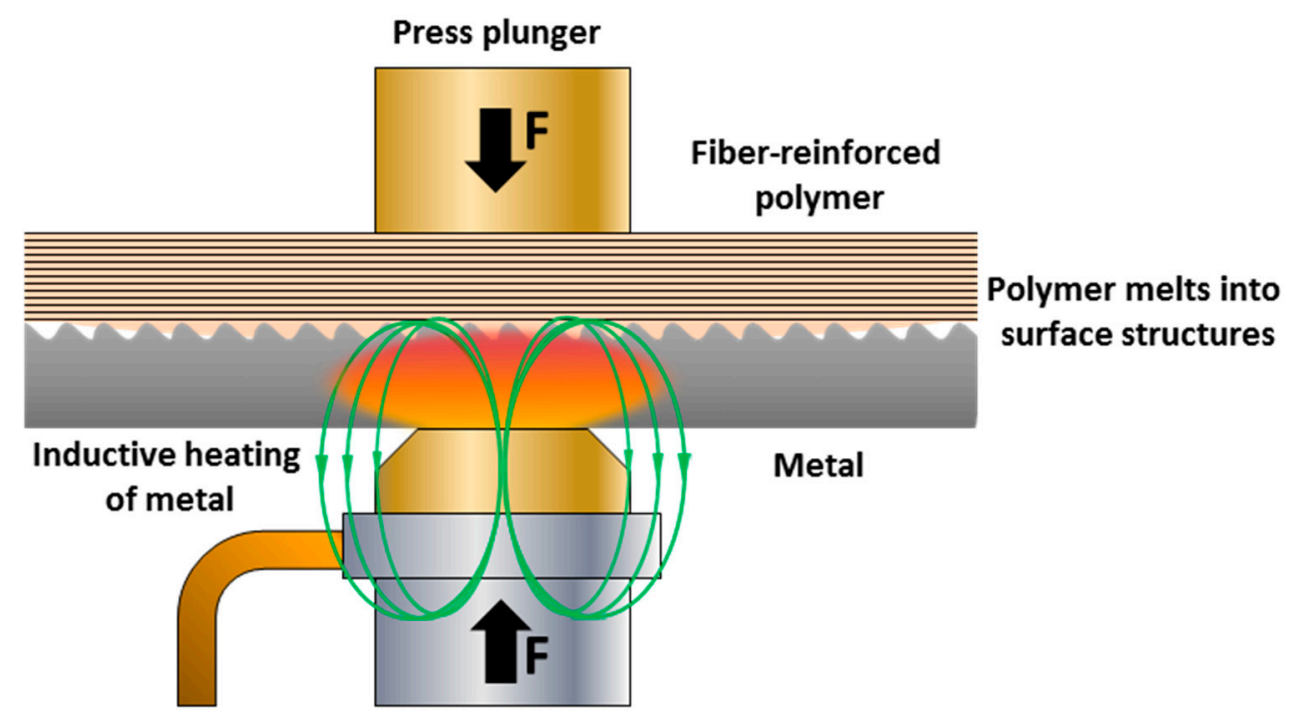

Figure 1. Principle of thermal direct joining.

Titanium is commonly used in high-performance engineering applications due to its high specific strength and superior corrosion resistance. Moreover, its biocompatibility makes it interesting for medical applications. PEEK exhibits a high toughness, fatigue resistance, and good thermal stability [18,19]. It can withstand long-term operation temperatures of up to $177^{\circ} \mathrm{C}$ and is therefore used in lightweight applications designed for elevated temperatures [20].

The performance of a joint is governed by multiple effects and depends on the mechanical, physical, and chemical properties of the involved surfaces [2]. An appropriate surface roughness, which provides a sufficiently large interface area, and a contamination-free surface, are among the key factors for ensuring good adhesion. Hence, various surface pre-treatments have been investigated for improving bond strength and durability, including surface roughening, wet-chemical cleaning, and the use of adhesion promoters [2,21]. Laser surface structuring is widely used for adjusting the surface roughness of the metallic counterpart of the joint. In contrast to other pre-treatment methods, it does not only increase the roughness for enlarging the surface area for adhesion, but also facilitates the generation of defined structures and patterns for mechanical interlocking. Thus, manifold surface morphologies with various dimensions of the surface features can be obtained. A significant increase in bond strength after laser structuring has been confirmed by several authors $[9,18,21,22]$.

Nevertheless, surface pre-treatment adds an additional step to the process chain of hybrid joint manufacturing. By contrast, additive manufacturing offers the possibility to directly include certain surface features during fabrication of the component. Moreover, additively manufactured parts possess an inherent surface roughness which could enable mechanical interlocking on the micrometer scale. Several studies have investigated different fields of additive manufacturing for enhancing adhesion or fabricating polymer-metal hybrid structures. Falck et al. developed the so-called AddJoining process based on fused deposition modeling (FDM), whereby a polymer filament is extruded through a nozzle and directly deposited on the metallic counterpart [5]. Brückner et al. used high-precision laser metal deposition (LMD) with powder and wire for generating microstructures, which successfully improved the adhesion of thermal barrier coatings for gas turbines [23,24]. Nguyen made use of laser powder bed fusion (LPBF) for manufacturing titanium with macro- and micron-sized features for hybrid joints. These hierarchical structures could substantially enhance bond strength due to micro-mechanical interlocking and crack deflection at the macro-structures [2]. Plettke et al. applied LPBF to manufacture aluminum and titanium samples with interlocking structures which were then joined to a thermoplastic composite sheet [25]. 
In this study, titanium samples with different surface structures were manufactured by means of electron beam melting (EBM). After the effectiveness of such structures for altering the bond strength of metal-polymer hybrid joints was shown in a preliminary study [26], the results are now presented in a broader context. Adhesive bonding and thermal direct joining of additively manufactured titanium and carbon fiber-reinforced PEEK were investigated. Bond strength and durability were assessed by means of tensile shear testing before and after salt spray testing. The aim of this study was to evaluate whether additively manufactured surfaces can provide a suitable interface for hybrid joints for structural lightweight applications.

\section{Materials and Methods}

\subsection{Sample Design}

The bond strength of the hybrid joints created by means of adhesive bonding and thermal direct joining should be assessed via tensile shear testing. In accordance with DIN EN 1465, all samples were designed as cuboids with a dimension of $105 \mathrm{~mm} \times 25 \mathrm{~mm} \times 2 \mathrm{~mm}$ [27]. The effectiveness of different surface structures for enhancing strength and stability of the bond should be evaluated. These structures should directly be integrated during electron beam melting of the tensile shear test specimens, thus exploiting the potential of additive manufacturing technologies to fabricate complex geometries. For this purpose, pins and grooves with trapezoidal cross sections were selected as interlocking structures. The geometries of the interlocking structures were adapted from a study by Klotzbach et al., in which the authors attained features with a similar shape by means of laser surface structuring [15]. The features' size was then adjusted to comply with the approximate attainable feature size resolution in electron beam melting. These groove- and pin-shaped features were included in the CAD sample design in such way that the patterns covered the entire section of the future overlap area using Autodesk Inventor 2016. Hereby, three basic additively manufactured sample groups were defined: "as-built", "grooves", and "pins", respectively. The "as-built" sample group comprised the specimens which exhibited the inherent surface roughness of additively manufactured parts, but possessed no additional designated interlocking features. The "grooves" and "pins" sample groups were designed with the groove- and pin-shaped structures in the area of the future overlapping length of the tensile shear specimens, respectively. In addition to that, two reference surface conditions were established, namely "laser surface structured" and "milled". The laser-structured specimen group, on the one hand, served as a benchmark for the state of the art in terms of bond strength of adhesive bonded and thermally direct joined specimens. On the other hand, the milled reference group was assumed to only provide a comparatively low bond strength due to its rather smooth surface. In this way, an adequate evaluation of the results obtained for the additively manufactured samples should be facilitated. The exact parameters of both reference conditions are explained further below. The dimensions and the design of the interlocking structures to be produced by additive manufacturing are presented in Figure 2. 


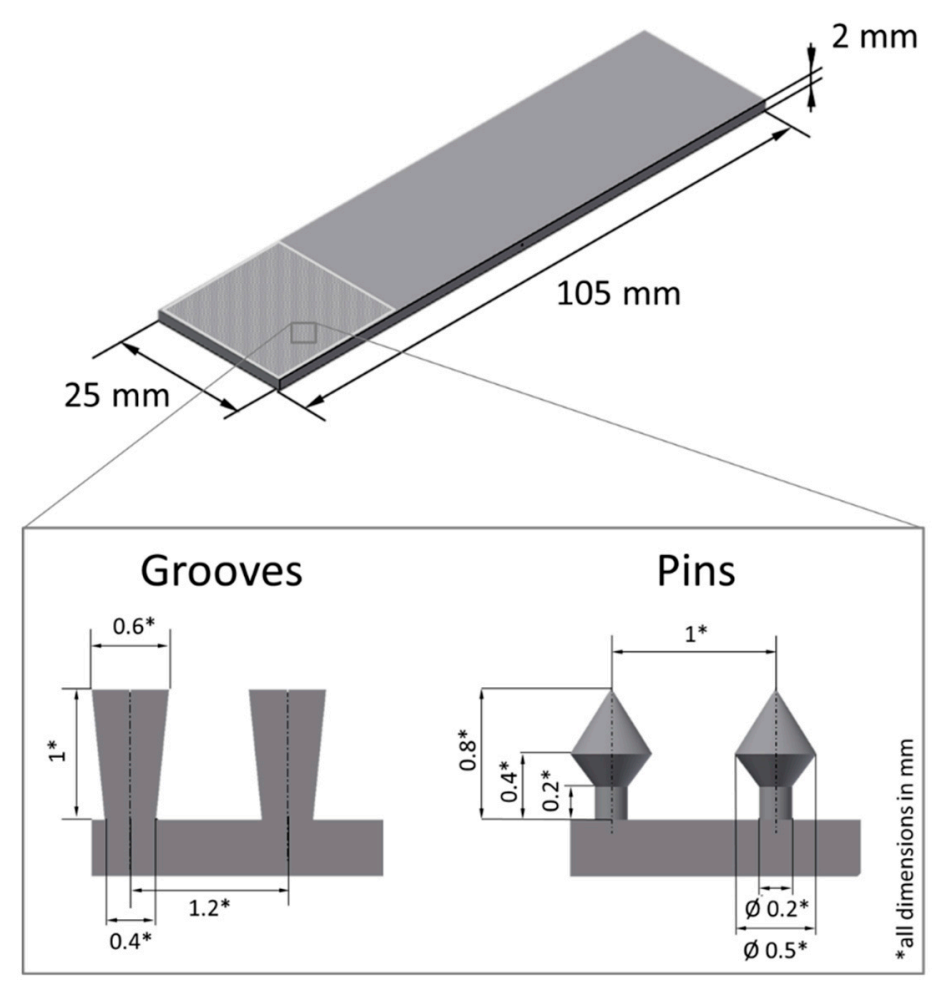

Figure 2. Geometry of tensile test specimens. The enlarged section shows the design and dimensions of the groove- and pin-shaped surface structures.

\subsection{Additive Manufacturing of Titanium Samples}

An Arcam A2X electron beam melting machine (Arcam AB, Mölndal, Sweden) was used for fabricating the titanium specimens. Titanium Ti-6Al-4V powder (GE Additive, particle size distribution $45-106 \mu \mathrm{m}$ ) was utilized. Electron beam melting is a powder bedbased additive manufacturing process which is characterized by the recurrent application of a powder layer and heat input using an electron beam. The heating step was divided into two sub-steps: first, a defocused beam was applied to sinter the powder and avoid so-called smoke effects, followed by the actual melting of the component cross section with a focused beam [28]. Figure 3 illustrates the orientation of the specimens on the substrate plate during manufacturing. The figure shows the fabrication of samples with pin-shaped structures, which are located within the darker shaded areas.

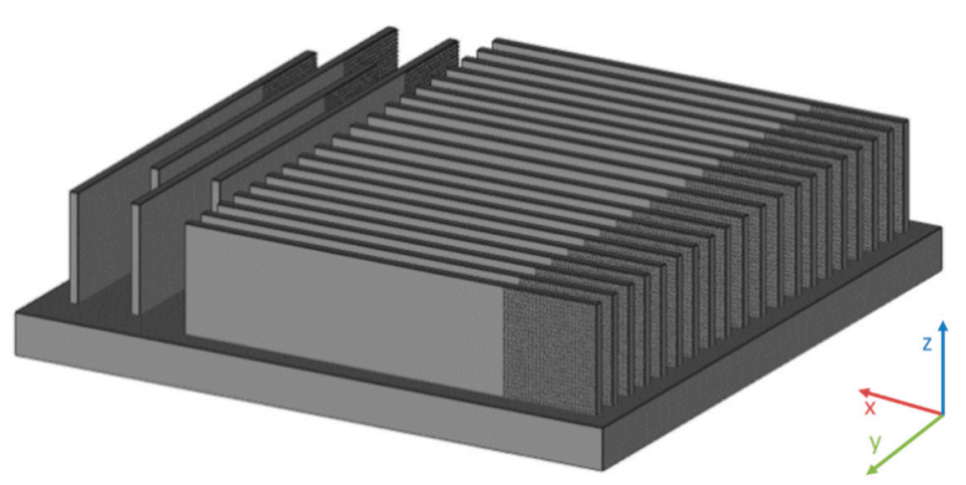

Figure 3. Position of tensile shear specimens on substrate plate.

The applied electron beam processing parameters for melting of the Ti-6Al-4V samples are summarized in Table 1. 
Table 1. Electron beam melting process parameters for Ti-6Al-4V specimens.

\begin{tabular}{cccccc}
\hline Voltage & $\begin{array}{c}\text { Beam } \\
\text { Current }\end{array}$ & Scan Speed & Focus Offset & $\begin{array}{c}\text { Layer } \\
\text { Thickness }\end{array}$ & $\begin{array}{c}\text { Preheat } \\
\text { Temperature }\end{array}$ \\
\hline $60 \mathrm{kV}$ & $15 \mathrm{~mA}$ & $4530 \mathrm{~mm} / \mathrm{s}$ & $3 \mathrm{~mA}$ & $50 \mu \mathrm{m}$ & $700{ }^{\circ} \mathrm{C}$ \\
\hline
\end{tabular}

To obtain the samples for the two reference groups, milling was applied on the area of the future overlapping length of the designated specimens. Approximately $200 \mu \mathrm{m}$ of material were removed until the typical rough appearance of additive components was no longer visible and a comparatively smooth surface was achieved. Half of those specimens remained in the milled surface state as the unstructured control group, while the other half underwent a further surface treatment step by means of laser structuring. A laser beam (IR fiber laser source, line distance $0.2 \mathrm{~mm}$, maximum scanning velocity $10 \mathrm{~m} / \mathrm{s}$ ) was scanned over the surface twice to attain the laser surface structured reference group, which allowed a comparison of the results within the state of the art $[9,15]$. The obtained surface structures were characterized by means of a KEYENCE VK-X250 laser scanning confocal microscope (KEYENCE Deutschland GmbH, Neu-Isenburg, Germany).

\subsection{Joining Processes}

The titanium specimens were then joined to the composite material using either adhesive bonding or thermal direct joining, respectively. Carbon fiber-reinforced PEEK (CF-PEEK) with a multi-axial non-crimp fabric and a fiber content of $60 \%$ as reinforcing material was used. The CF-PEEK was cut into $105 \mathrm{~mm} \times 25 \mathrm{~mm} \times 2 \mathrm{~mm}$ pieces prior to joining.

For adhesive bonding, a single-component epoxy-based adhesive $\left(\mathrm{DELO}{ }^{\circledR} \mathrm{MONOPOX}\right.$ AD066) was applied on both sides of the surfaces to be joined. Then, both joint partners were brought together at the overlapping length of $12.5 \mathrm{~mm}$. After bonding, the specimens were cured for three hours at $130^{\circ} \mathrm{C}$.

In the case of thermal direct joining, a PEEK foil with a thickness of $0.4 \mathrm{~mm}$ was inserted between the metal and the composite component to serve as a hot-melt in order to achieve a good bonding between both joint partners. As with adhesive bonding, specimens were joined with an overlapping length of $12.5 \mathrm{~mm}$. A joining gun was utilized to locally apply a press force of $300 \mathrm{~N}$ at the joining zone. An EFD Minac 18/25 generator in the medium- to high-frequency range was used for inductive heating during thermal direct joining. Subsequently, the joining zone was cooled by means of pressurized air before the applied pressure was released.

\subsection{Characterization of Titanium-CFRP Hybrid Joints}

Metallographic cross sections of the bonded specimens with the pin- and grooveshaped surface structures were examined with an Olympus GX51 inverted metallurgical microscope (Olympus Deutschland $\mathrm{GmbH}$, Hamburg, Germany) to investigate how well these features were embedded in the CF-PEEK material.

Tensile shear testing was carried out at room temperature in accordance with DIN EN 1465 [27]. A Zwick Z050 multiaxial material testing machine (Zwick GmbH \& Co., Ulm, Germany) with a preload of $5 \mathrm{~N}$ and a test speed of $10 \mathrm{~mm} / \mathrm{min}$ was used for testing. Zwick 8355 testing clamps (Zwick GmbH \& Co., Ulm, Germany) were used for fixation of the specimens during testing. Three specimens of each sample group were tested. Non-contact optical strain measurements based on grayscale analysis were performed on selected samples during tensile shear testing using a GOM ARAMIS 5M system.

For analyzing bond stability, the respective sample groups were subjected to salt spray testing in a Weiss Umwelttechnik SC/KWT 450 brine spray test cabinet (Weiss Umwelttechnik GmbH, Stuttgart, Germany) according to DIN EN ISO 9227 for a duration of $1000 \mathrm{~h}$ [29]. Subsequently, the residual tensile shear strength was tested as described above. 


\section{Results}

In this study, the effect of different additively manufactured surface structures on bond strength and bond stability of hybrid titanium/CF-PEEK joints was investigated.

The surface structures obtained via electron beam melting and the two reference groups were evaluated by visual inspection and by means of laser scanning confocal microscopy. Roughness was evaluated from multiple line scans (10 neighboring lines with a distance of four pixels) from six randomly selected measuring areas on the confocal microcopy images. A Gaussian filter with the cutoff values $\lambda_{\mathrm{s}}=2.5 \mu \mathrm{m}$ and $\lambda_{\mathrm{c}}=0.8 \mathrm{~mm}$ was applied. However, it was not possible to determine a meaningful roughness value for the groove- and pin-shaped structures with the employed optical measurement method due to the undercuts. The surface characteristics of the three additively manufactured sample groups and the two control groups are illustrated in Figure 4, respectively.
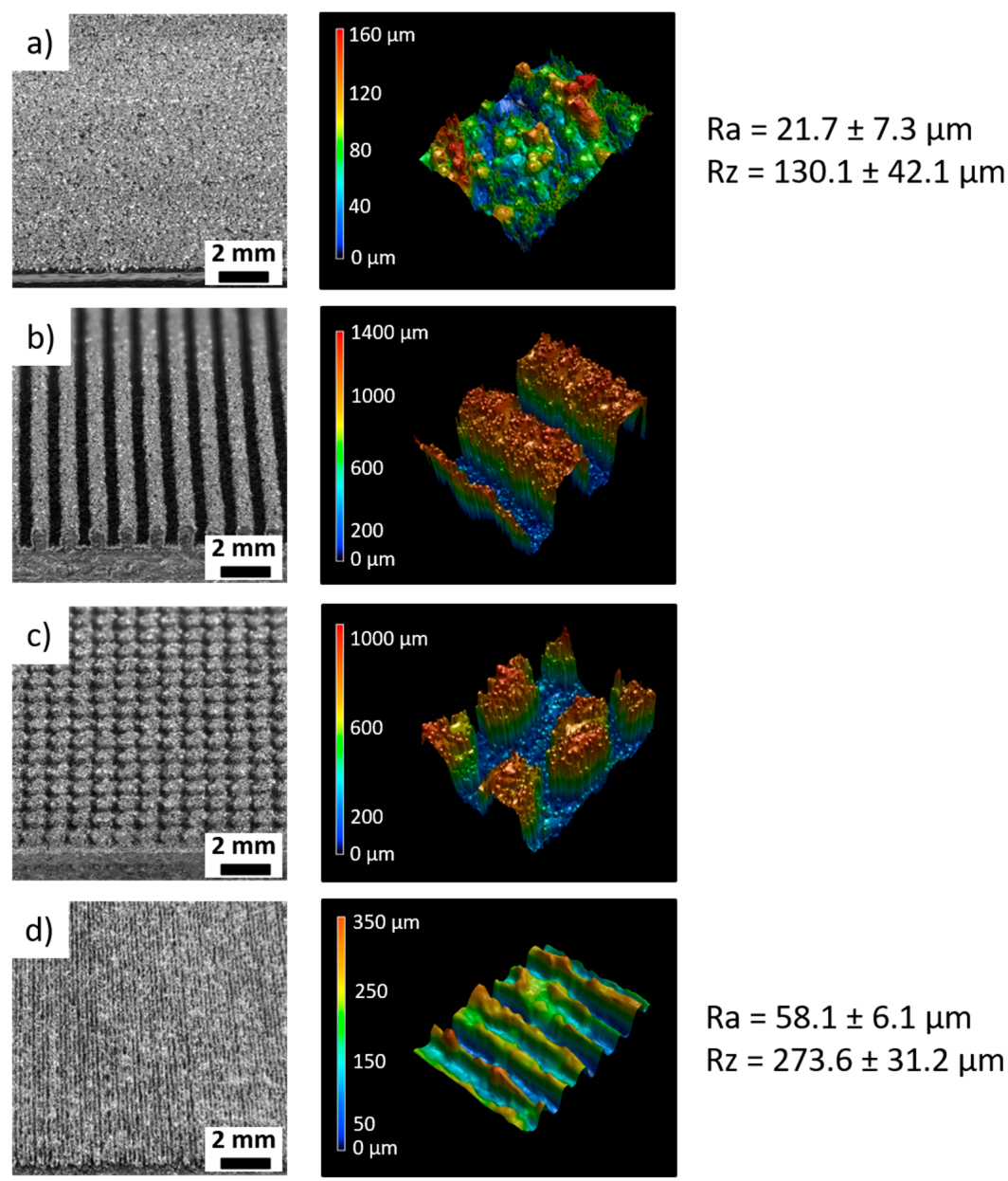

$\mathrm{Ra}=58.1 \pm 6.1 \mu \mathrm{m}$
$\mathrm{Rz}=273.6 \pm 31.2 \mu \mathrm{m}$
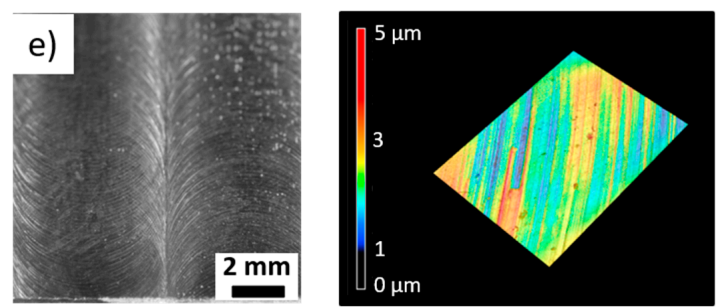

$\mathrm{Ra}=0.4 \pm 0.1 \mu \mathrm{m}$

$\mathrm{Rz}=2.7 \pm 0.8 \mu \mathrm{m}$

Figure 4. Close-up view (left) and laser scanning confocal microscopy images (right) of titanium samples with (a) as-built surface, (b) groove-shaped surface structures, (c) pin-shaped surface structures, (d) laser structured surface, (e) milled surface. If applicable, the roughness values Ra and $\mathrm{Rz}$ are presented next to the confocal microscopy images. 
All three EBM-manufactured specimens exhibited a rough surface with adhering or partly molten particles, which is typical of powder bed-based additive manufacturing processes [28]. Especially for the groove- and pin-shaped structures, it became apparent that the EBM process had a limited feature size resolution, which was influenced by several factors such as melt pool size and particles sticking to the surfaces [30]. Hence, the obtained surface structures deviated from the original CAD design both in size and shape. The confocal microscopy images provided a three-dimensional impression of the specimen surfaces. However, the method is not suited for detecting complex geometries such as undercuts and therefore only allows a qualitative inspection of the generated surface features. It was therefore not possible to determine a roughness value for the surfaces with the groove- and pin-shaped structures (Figure $4 b, c)$. In the case of the laser structured surfaces, a relatively regular pattern of adjacent lines is visible in Figure $4 \mathrm{~d}$. The surface roughness of the laser structured reference samples significantly exceeded the roughness measured for the as-built specimens (Figure 4a). The milled control group (Figure 4e) had a comparatively smooth surface and only showed the distinct tool marks from face milling. Hence, only a low surface roughness was measured for these samples.

Figure 5 shows the metallographic cross sections which were prepared from the groove- and pin-shaped specimens after adhesive bonding and thermal direct joining to the composite material, respectively.
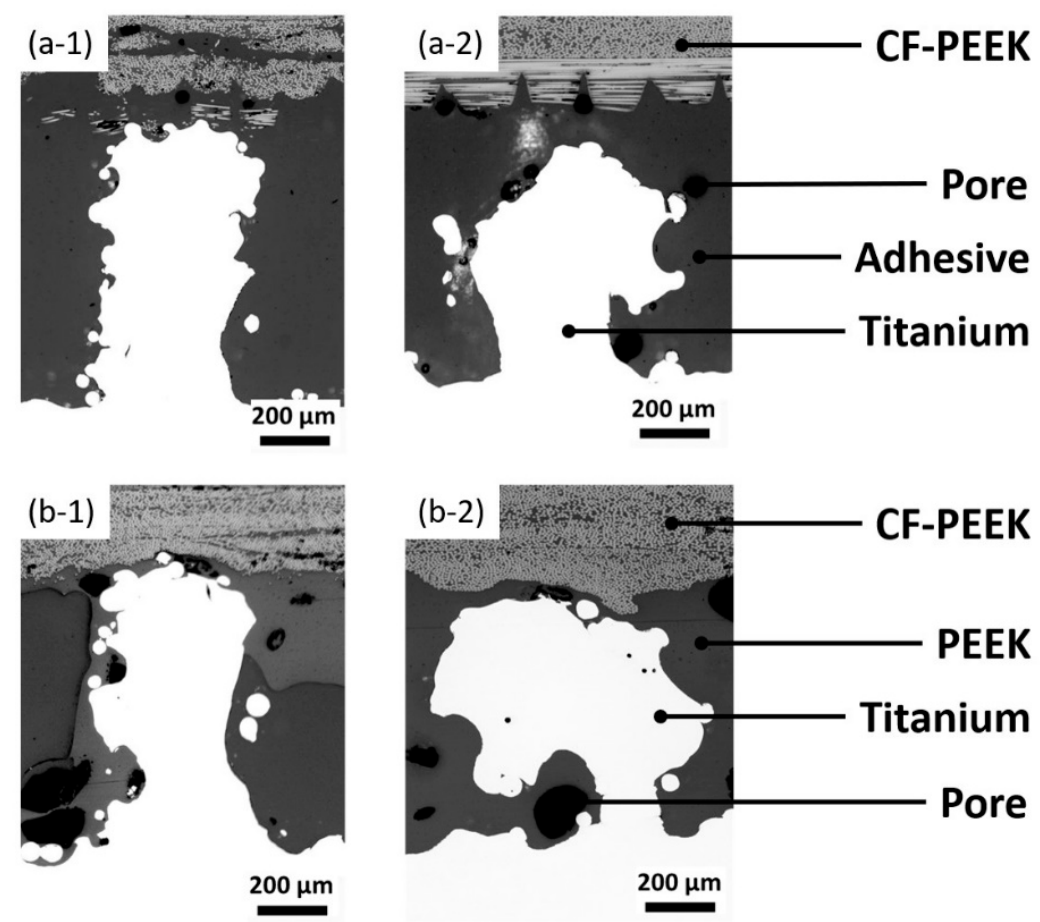

Figure 5. Metallographic cross section of (a-1) and (a-2) adhesive bonded and (b-1) and (b-2) thermally direct joined specimens with (a-1) and (b-1) groove-shaped and (a-2) and (b-2) pin-shaped surface structures.

In all cases, the adhering and partly molten particles from the additive manufacturing process could clearly be detected. The grooves and pins were almost completely embedded in the adhesive with just a few pores in the joining zone, whereas larger pores were visible in the case of thermal direct joining. It is possible that the thickness of the PEEK film was not sufficient to provide enough hot-melt to fully surround the surface features.

Furthermore, it was evident from the cross sections that the surface structures did not penetrate the CF-PEEK composite as a consequence of the high fiber content.

The tensile shear strength values for the adhesive bonded specimens before and after salt spray testing are depicted in Figure 6. 


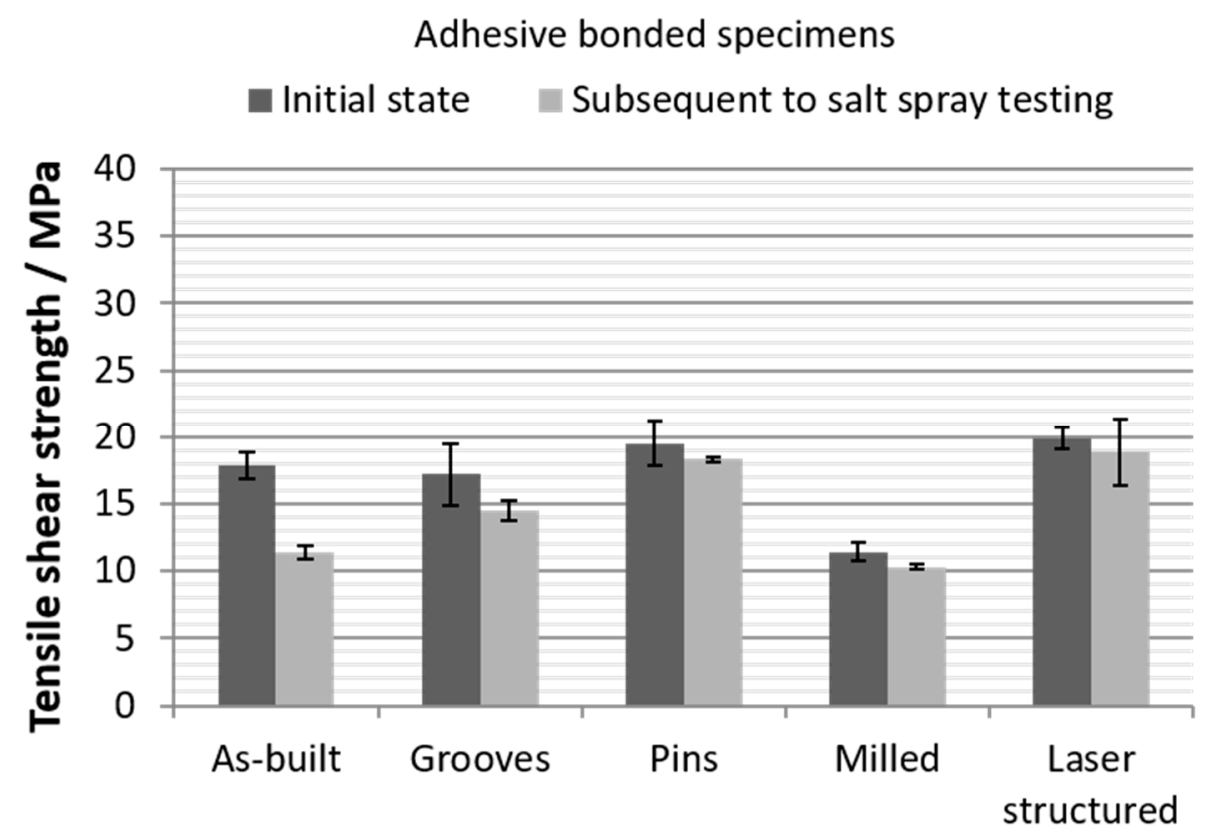

Figure 6. Tensile shear strength of adhesive bonded specimens in the initial state and after salt spray testing for $1000 \mathrm{~h}$.

The initial shear strength of all additively manufactured structures was comparable to the values achieved with laser surface structuring. Pins seemed to be particularly favorable, as some specimens showed even better results than the laser structured control group, although the results obtained with the pin structures showed a greater standard deviation. At the same time, a significant improvement in bond strength in comparison to the milled control group was found for both the as-built and the groove- and pin-shaped structures.

The shear strength of all samples decreased as a consequence of salt spray testing. The largest drop could be observed for the as-built specimens, followed by the samples with groove-shaped structures. Interestingly, only a rather small decline in strength was observed for the milled reference group, suggesting that this adhesive bond was relatively stable under salt spray conditions. Nevertheless, the absolute values of the retained strength were conspicuously lower for the milled specimen than for all other sample groups.

Figure 7 visualizes the tensile shear strengths of the hybrid joints fabricated by means of thermal direct joining both prior to and after salt spray testing, respectively.

The tensile shear samples with the milled metal surface could not be tested, because the samples fell apart either immediately after thermal direct joining or during sample handling prior to testing. Hence, the milled reference group is not included in Figure 7. Regarding the initial shear strength, there was a tendency that the values obtained with the additively manufactured specimens even exceeded those for the laser structured sample surface. Similar to adhesive bonding, the best results were obtained with the pin surface features. However, after salt spray exposure, a significant decline in bond strength was measured for all additive manufactured sample groups, whereas the laser structured reference group on average retained its full shear strength. The most pronounced effect of salt spray testing could be noticed for the pin structures.

Table 2 summarizes the tensile shear strength values before and after salt spray testing as well as the retained strength for both joining methods. 


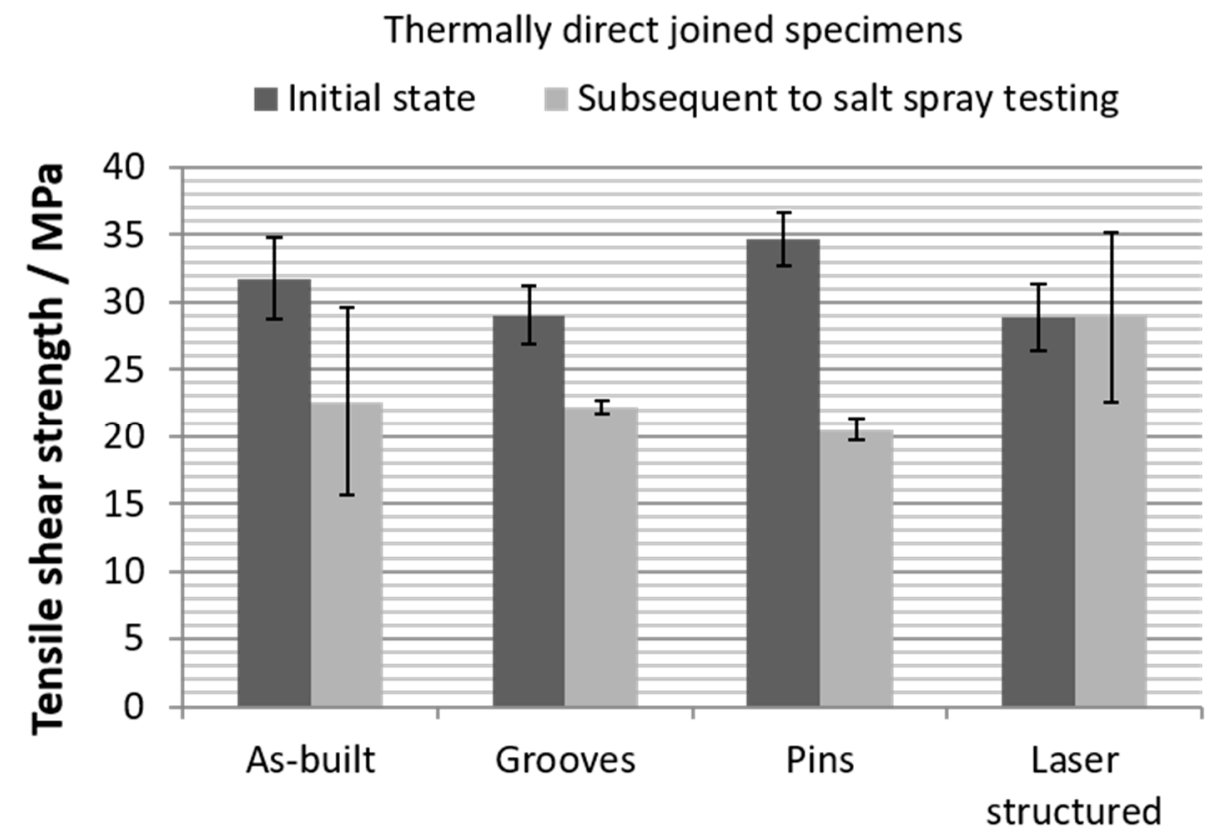

Figure 7. Tensile shear strength of thermally direct joined specimens in the initial state and after salt spray testing for $1000 \mathrm{~h}$.

Table 2. Overview of initial tensile shear strength and retained tensile shear strength after salt spray testing for adhesive bonded and thermally direct joined specimens.

\begin{tabular}{|c|c|c|c|c|c|c|}
\hline \multirow{2}{*}{$\begin{array}{c}\begin{array}{c}\text { Joining } \\
\text { Method }\end{array} \\
\begin{array}{c}\text { Surface } \\
\text { Condition }\end{array}\end{array}$} & \multicolumn{3}{|c|}{ Adhesive Bonding } & \multicolumn{3}{|c|}{ Thermal Direct Joining } \\
\hline & $\begin{array}{c}\text { Initial Tensile } \\
\text { Shear Strength } \\
\text { (MPa) }\end{array}$ & $\begin{array}{l}\text { Tensile Shear } \\
\text { Strength after } \\
\text { SST }^{1}(\mathrm{MPa})\end{array}$ & $\begin{array}{c}\text { Retained } \\
\text { Tensile Shear } \\
\text { Strength }(\%)\end{array}$ & $\begin{array}{c}\text { Initial Tensile } \\
\text { Shear Strength } \\
\text { (MPa) }\end{array}$ & $\begin{array}{c}\text { Tensile Shear } \\
\text { Strength after } \\
\text { SST }^{1}(\mathrm{MPa})\end{array}$ & $\begin{array}{c}\text { Retained } \\
\text { Tensile Shear } \\
\text { Strength (\%) }\end{array}$ \\
\hline As-built & $17.8 \pm 1.0$ & $11.4 \pm 0.5$ & $64.0 \%$ & $31.7 \pm 3.0$ & $22.6 \pm 7.0$ & $71.1 \%$ \\
\hline Grooves & $17.2 \pm 2.3$ & $14.5 \pm 0.8$ & $84.3 \%$ & $29.1 \pm 2.2$ & $22.2 \pm 0.5$ & $76.5 \%$ \\
\hline Pins & $19.5 \pm 1.7$ & $18.3 \pm 0.2$ & $93.8 \%$ & $34.7 \pm 1.9$ & $20.5 \pm 0.8$ & $59.1 \%$ \\
\hline Milled & $11.4 \pm 0.7$ & $10.3 \pm 0.2$ & $90.4 \%$ & -2 & -2 & -2 \\
\hline $\begin{array}{l}\text { Laser surface } \\
\text { structured }\end{array}$ & $19.9 \pm 0.8$ & $18.9 \pm 2.5$ & $94.8 \%$ & $28.9 \pm 2.5$ & $28.9 \pm 6.3$ & $100.0 \%$ \\
\hline
\end{tabular}

${ }^{1}$ Salt spray testing. ${ }^{2}$ No stable bond was created in the case of the milled specimens. All samples fell apart prior to testing.

The laser structured specimens appear to have good resistance to the corrosive environment, while the other specimens showed varying sensitivity to the salt spray exposure depending on the joining process.

Exemplary still frames from optical strain measurements are shown in Figure 8.

The images indicate that cracks might be deflected at the groove- and pin-shaped structures, since they are clearly visible in the digital image correlation. Apart from that, the measurements suggest that there might be an additional bending moment which could be caused by the protruding surface structures. 


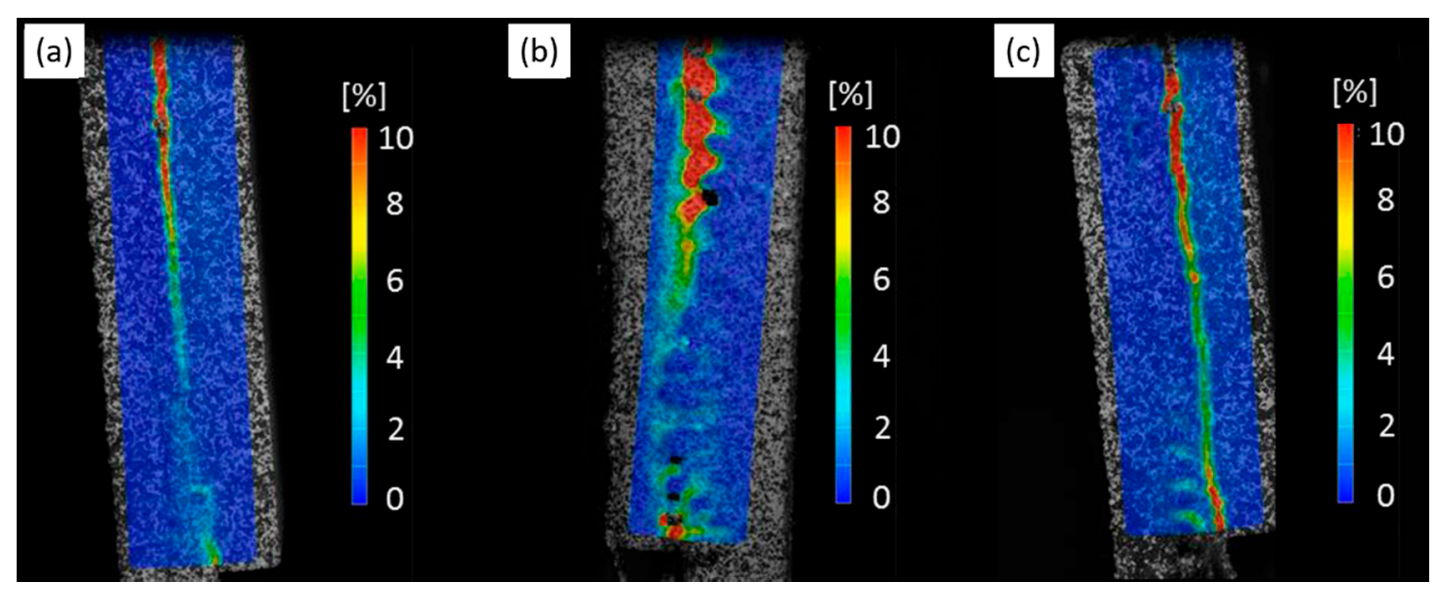

Figure 8. Optical strain measurement during tensile shear testing of thermally direct joined carbon fiber-reinforced polyether-ether-ketone (CF-PEEK) with additive manufactured titanium with (a) as-built surface, (b) groove-shaped surface structures, and (c) pin-shaped surface structures.

\section{Discussion}

Several studies have confirmed that an increase in surface roughness on the metal counterpart of a hybrid joint, e.g., by means of laser surface structuring, can lead to a considerable improvement in bond strength $[9,18,21]$. Additive manufacturing technologies, such as laser powder bed fusion or electron beam melting, offer the opportunity to manufacture complex features for macro-mechanical interlocking with no additional effort and possess an inherent surface roughness, which might further contribute to the strength of the envisaged bond. Therefore, the influence of additively manufactured as-built, groove-, and pin-shaped surface structures on both bond strength and stability after salt spray exposure of adhesive bonded and thermally direct joined titanium-/CF-PEEK composites was investigated. Laser structured surfaces on the one hand and milled surfaces on the other hand served as reference samples for state-of-the-art technology and unstructured surfaces, respectively.

It was found that all additive manufactured surface structures performed significantly better in terms of tensile shear strength than the milled reference group regardless of the joining method. It is remarkable that even the as-built surfaces with no designated interlocking structures achieved initial shear strength values which were comparable to or even better than the laser surface structured specimens, particularly in the case of thermal direct joining. The inherent surface roughness and the adhered particles might have led to a micro-interlocking effect and an enlarged surface area compared to a totally flat surface. This assumption is supported by findings reported by Woitun et al., who stated that an increase in true surface area and a uniform distribution of stress, which can be obtained by evenly distributed surface features, are among the most important factors for enhancing the bond strength of metal-polymer hybrid joints [31]. Nevertheless, the hybrid joints with the as-built metal counterpart surfaces appeared to be susceptible to degradation in salt spray conditions.

Both the groove- and the pin-shaped surface structures seemed to be effective features for macro-mechanical interlocking. The pins resulted in the overall highest initial shear strengths of all additive sample groups and even exceeded the values achieved with laser surface structuring in the case of thermal direct joining. In contrast, the sample group with the groove-shaped structures lagged slightly behind the as-built group regarding initial strength. These observations support the assumption that size and shape of the surface structures could play a substantial role in the performance of the joint.

Regarding salt spray testing, it was found that the laser structured reference group had the highest retained strength after $1000 \mathrm{~h}$ both for adhesive bonding and thermal direct joining. While the pin structures seemed to be beneficial for the long-term stability 
of the adhesive bonded specimens, that sample group lost more than $40 \%$ of its original bond strength due to salt spray exposure after thermal direct joining. In the case of the groove-shaped surface structures, the reduction in strength after salt spray testing was also more pronounced for thermal direct joining than for adhesive bonding. One possible explanation might be that the adhesive created a barrier layer between the metal and the fiber-reinforced polymer component, thus effectively decelerating diffusion and impeding corrosion on either of the components. Regarding thermal direct joining, the metallographic cross sections show that the amount of PEEK hot-melt was not sufficient to fully embed the additively manufactured macrostructures. The resulting voids may have accelerated diffusion processes at the interface between the metal and the polymer and thus aggravated the degradation [14]. It is also conceivable that galvanic corrosion occurred where the titanium structures came into direct contact with free carbon fibers. Galvanic corrosion as a consequence of salt spray testing has been reported for aluminum-CFRP and aluminumtitanium-CFRP hybrid joints [32]. A potential solution for improving bond durability for thermal direct joining could be to increase the amount of PEEK that is used as a hot-melt between the two counterparts. This might not only slow down corrosion and degradation by reducing the size and number of voids, but could also have a beneficial effect on initial shear strength. By adding a PEEK interlayer at the joining zone of a steel/CF-PEEK hybrid joint, Mitschang et al. could successfully prevent corrosion and increase tensile shear strength by $55 \%$ [13].

Comparing adhesive bonding and thermal direct joining in terms of absolute tensile shear strength, thermal direct joining resulted in significantly higher bond strengths for all sample groups. In the case of adhesive bonding, adhesion might have been hampered by titanium surface oxide layers on the one hand [18] and by the low wettability of the CFPEEK [33] on the other hand. In contrast, the relative reduction in strength was more severe for the thermally direct joined specimens than for the adhesive bonded ones. As described above, the insufficient amount of PEEK hot-melt at the interface between titanium and CF-PEEK is assumed as the main reason for this observation.

With the progressive application of additive manufacturing processes, the joining of additively manufactured components is also becoming more and more relevant [34]. The results obtained in this study indicate that the inherent surface roughness of additively manufactured parts has a beneficial effect on the bond strength of metal-CFRP hybrid joints in comparison to flat, unstructured surfaces. Bond strength might further be enhanced by using appropriate interlocking surface features, which could directly be implemented during the additive manufacturing process. Pin-shaped surface structures were found to be particularly suitable in this study. Since the tensile shear strengths of most sample groups with additive manufactured surfaces were competitive to or even better than those achieved with state-of-the-art laser surface structuring, it might be possible to omit this additional pre-treatment step in some applications. This might be especially interesting for complex lightweight components in the aerospace or automotive sectors. Potential applications might include aircraft components for stringers, j-nose panels, landing gear, or fan blades. Apart from in the transport industry, these hybrid joints might also enable novel designs and applications in biomedicine, e.g., for orthoses or prostheses.

However, caution should be exercised with regard to the durability of those joints composed of additive manufactured metals and fiber-reinforced composites, as they were found to be susceptible to degradation of bond stability in salt spray testing. The applicability of such structures under certain environmental conditions might therefore be limited.

For this reason, future research should target a profound understanding of the interrelation between joint design and bond stability in harsh environments for additively manufactured structures. Moreover, the design of the macrostructures for optimizing bond strength should be investigated in depth. One option would be the use of laser powder bed fusion instead of electron beam melting, which allows the fabrication of smaller and more defined patterns. 


\section{Conclusions}

The objective of this study was to investigate the effect of different surface structures fabricated via electron beam melting on the performance of titanium/CF-PEEK hybrid joints. These joints were created by adhesive bonding and thermal direct joining, respectively. In order to evaluate the bond stability, tensile shear tests were conducted before and after salt spray testing. The results were compared to the shear strengths of two reference groups, for which the titanium surfaces had either been milled or laser-structured.

It was found that regardless of the joining method, the tensile shear strength values of the additively manufactured specimens exceeded the ones obtained for the milled reference group. Remarkably, even the as-built sample surface with no designated surface features showed very promising results in terms of initial shear strength, which surpassed the laserstructured reference group in the case of thermal direct joining. It was therefore assumed that the inherent surface roughness, which is characteristic for additive manufacturing processes, fosters micro-mechanical interlocking at the interface between the metal and the composite counterpart of the joint.

Regarding the additively manufactured surface structures, the pin-shaped features especially seemed to facilitate macro-mechanical interlocking, resulting in initial bond strengths which were competitive to or even higher than those of the laser-structured reference specimens.

However, the additively manufactured specimens appeared to be particularly susceptible to bond degradation during salt spray testing. This effect was more pronounced for thermal direct joining than for adhesive bonding, presumably due to an insufficient embedment of the surface structures in the PEEK hot-melt.

Additive manufacturing thus provides a viable alternative for the production of metalCFRP hybrid joints, which might be especially relevant for complex structural lightweight components in the aerospace or automotive sectors. Nevertheless, when implementing such structures, special attention should be paid to the durability of the bonds under harsh environmental conditions.

Author Contributions: Conceptualization: J.M., P.G., T.S., A.K.; methodology: J.M., P.G., T.S.; software: J.M.; validation: J.M., P.G.; formal analysis: J.M., P.G., T.S.; investigation: J.M., P.G., T.S.; resources: L.S., A.K., J.S.; data curation: J.M., P.G.; writing—original draft preparation: J.M.; writingreview and editing: J.M., P.G., T.S., L.S., A.K., J.S., E.L., F.B., C.L.; visualization: J.M.; supervision: L.S., A.K., J.S., E.L., F.B., C.L.; project administration: A.K., L.S., E.L. All authors have read and agreed to the published version of the manuscript.

Funding: This research received no external funding.

Conflicts of Interest: The authors declare no conflict of interest.

\section{References}

1. Rosenthal, S.; Maaß, F.; Kamaliev, M.; Hahn, M.; Gies, S.; Tekkaya, A.E. Lightweight in Automotive Components by Forming Technology. Automot. Innov. 2020, 3, 195-209. [CrossRef]

2. Nguyen, T. Nature Inspired Aerospace Hybrid Structural Joint Concepts Realised by Additive Manufacturing. Ph.D. Thesis, RMIT University, Melbourne, Australia, April 2017.

3. Schuett, M.; Karsten, J.; Schott, L.; Wittich, H.; Schulte, K.; Fiedler, B. Experimental and analytical study of an CF-PEEK Fastener all composites single-lap shear joint under static and fatigue loading. CEAS Aeronaut. J. 2018, 10, 565-587. [CrossRef]

4. Cortes, P.; Cantwell, W. Structure-properties relations in titanium-based thermoplastic fiber-metal laminates. Polym. Compos. 2006, 27, 264-270. [CrossRef]

5. Falck, R.; Goushegir, S.; Dos Santos, J.; Amancio-Filho, S. AddJoining: A novel additive manufacturing approach for layered metal-polymer hybrid structures. Mater. Lett. 2018, 217, 211-214. [CrossRef]

6. Flock, D. Heat Conduction Bonding of Plastic-Metal Hybrid Parts. Ph.D. Thesis, RWTH Aachen University, Aachen, Germany, December 2011.

7. Zhou, W.; Zhang, R.; Ai, S.; He, R.; Pei, Y.; Fang, D. Load distribution in threads of porous metal-ceramic functionally graded composite joints subjected to thermomechanical loading. Compos. Struct. 2015, 134, 680-688. [CrossRef]

8. Zhou, W.; Ai, S.; Chen, M.; Zhang, R.; He, R.; Pei, Y.; Fang, D. Preparation and thermodynamic analysis of the porous ZrO2/(ZrO2 + Ni) functionally graded bolted joint. Compos. Part B Eng. 2015, 82, 13-22. [CrossRef] 
9. Gebauer, J.; Fischer, M.; Lasagni, A.F.; Kühnert, I.; Klotzbach, A. Laser structured surfaces for metal-plastic hybrid joined by injection molding. J. Laser Appl. 2018, 30, 032021. [CrossRef]

10. Kweon, J.-H.; Jung, J.-W.; Kim, T.-H.; Choi, J.-H.; Kim, D.-H. Failure of carbon composite-to-aluminum joints with combined mechanical fastening and adhesive bonding. Compos. Struct. 2006, 75, 192-198. [CrossRef]

11. Fink, A.; Camanho, P.; Andrés, J.; Pfeiffer, E.; Obst, A. Hybrid CFRP/titanium bolted joints: Performance assessment and application to a spacecraft payload adaptor. Compos. Sci. Technol. 2010, 70, 305-317. [CrossRef]

12. Roesner, A.; Scheik, D.-I.S.; Olowinsky, A.; Gillner, A.; Poprawe, R.; Schleser, M.; Reisgen, U. Innovative approach of joining hybrid components. J. Laser Appl. 2011, 23, 32007. [CrossRef]

13. Mitschang, P.; Velthuis, R.; Didi, M. Induction Spot Welding of Metal/CFRPC Hybrid Joints. Adv. Eng. Mater. 2013, 15, 804-813. [CrossRef]

14. Scheik, S. Untersuchungen des Verbundverhaltens von Thermisch Direkt Gefügten Metall-Kunststoffverbindungen unter Veränderlichen Umgebungsbedingungen; Shaker Verlag: Düren, Germany; Maastricht, Germany, 2016.

15. Klotzbach, A.; Langer, M.; Pautzsch, R.; Standfuß, J.; Beyer, E. Thermal direct joining of metal to fiber reinforced thermoplastic components. J. Laser Appl. 2017, 29, 022421. [CrossRef]

16. Klotzbach, A. Laser Joining Process Yields Metal-Thermoplastic Hybrid Parts. Ind. Laser Solut. 2019, 18-21. Available online: https: / / www.industrial-lasers.com/welding/article/16484546/laser-joining-process-yields-metalthermoplastic-hybrid-parts (accessed on 17 December 2020).

17. Schulze, K.; Hausmann, J.; Heilmann, S.; Wielage, B. Bruchmechanische Untersuchung der Titan-PEEK-Grenzfläche in thermoplastischen Titan-CF/PEEK-Laminaten durch Mixed-Mode-Bending-Versuche. Mater. Werkst. 2014, 45, 537-545. [CrossRef]

18. Henriques, B.; Sampaio, M.; Buciumeanu, M.; Souza, J.C.M.; Gomes, J.R.; Silva, F.S.; Carvalho, Ó. Laser surface structuring of Ti6Al4V substrates for adhesion enhancement in Ti6Al4V-PEEK joints. Mater. Sci. Eng. C 2017, 79, 177-184. [CrossRef] [PubMed]

19. Cortes, P.; Cantwell, W. The Tensile and Fatigue Properties of Carbon Fiber-reinforced PEEK-Titanium Fiber-metal Laminates. J. Reinf. Plast. Compos. 2004, 23, 1615-1623. [CrossRef]

20. Ramulu, M.; Stickler, P.; McDevitt, N.; Datar, I.; Kim, D.; Jenkins, M. Influence of processing methods on the tensile and flexure properties of high temperature composites. Compos. Sci. Technol. 2004, 64, 1763-1772. [CrossRef]

21. Zimmermann, S.; Specht, U.; Spiess, L.; Romanus, H.; Krischok, S.; Himmerlich, M.; Ihde, J. Improved adhesion at titanium surfaces via laser-induced surface oxidation and roughening. Mater. Sci. Eng. A 2012, 558, 755-760. [CrossRef]

22. Schulze, K.; Hausmann, J.; Wielage, B. The Stability of Different Titanium-PEEK Interfaces against Water. Procedia Mater. Sci. 2013, 2, 92-102. [CrossRef]

23. Brueckner, F.; Riede, M.; Finaske, T.; Seidel, A.; Nowotny, S.; Leyens, C.; Beyer, E. Additive Manufacturing with High-Performance Materials and Light-Weight Structures by Laser Metal Deposition and Laser Infiltration. LIA Today 2015, 2015, 736-739.

24. Brueckner, F.; Riede, M.; Marquardt, F.; Willner, R.; Seidel, A.; Thieme, S.; Leyens, C.; Beyer, E. Process characteristics in high-precision laser metal deposition using wire and powder. J. Laser Appl. 2017, 29, 022301. [CrossRef]

25. Plettke, R.; Schaub, A.; Gröschel, C.; Scheitler, C.; Vetter, M.; Hentschel, O.; Ranft, F.; Merklein, M.; Schmidt, M.; Drummer, D. A New Process Chain for Joining Sheet Metal to Fibre Composite Sheets. Key Eng. Mater. 2014, 1468-1475. [CrossRef]

26. Moritz, J.; Götze, P.; Schiefer, T.; Klotzbach, A.; Standfuß, J.; López, E.; Brueckner, F.; Leyens, C. Joining of Additively Manufactured Titanium with Different Surface Structures with Fiber-Reinforced PEEK for Lightweight Design Applications. In Proceedings of the 4th International Conference Hybrid 2020 Materials and Structures, Web-Conference, Karlsruhe, Germany, 28-29 April 2020.

27. DIN EN 1465:2009-07. Adhesives-Determination of Tensile Lap-Shear Strength of Bonded Assemblies. German Institute for Standardisation, 2009; 1465, (In German). [CrossRef]

28. Debroy, T.; Wei, H.; Zuback, J.; Mukherjee, T.; Elmer, J.; Milewski, J.; Beese, A.; Wilson-Heid, A.; De, A.; Zhang, W. Additive manufacturing of metallic components-Process, structure and properties. Prog. Mater. Sci. 2018, 92, 112-224. [CrossRef]

29. DIN EN ISO 9227:2017. Corrosion Tests in Artificial Atmospheres-Salt Spray Tests (ISO 9227:2017). German Institute for Standardisation, 2017; (In German). [CrossRef]

30. Riedlbauer, D.; Scharowsky, T.; Singer, R.F.; Steinmann, P.; Körner, C.; Mergheim, J. Macroscopic simulation and experimental measurement of melt pool characteristics in selective electron beam melting of Ti-6Al-4V. Int. J. Adv. Manuf. Technol. 2017, 88, 1309-1317. [CrossRef]

31. Woitun, D.; Roderus, M.; Bein, T.; Kroner, E. Precise laser structures as a tool to understand metal-polymer joints. J. Laser Appl. 2020, 32, 032003. [CrossRef]

32. Mehner, A.; Von Hehl, A.; Zoch, H.-W. Galvanic corrosion of aluminum wrought alloys in integral hybrid components with carbon fiber reinforced plastics (CFRP) and titanium. Mater. Corros. 2018, 69, 648-660. [CrossRef]

33. Riveiro, A.; Soto, R.; Comesaña, R.; Boutinguiza, M.; Del Val, J.; Quintero, F.; Lusquiños, F.; Pou, J. Laser surface modification of PEEK. Appl. Surf. Sci. 2012, 258, 9437-9442. [CrossRef]

34. Koch, C.; Richter, J.; Vollmer, M.; Kahlmeyer, M.; Niendorf, T.; Böhm, S. Adhesively bonded joints in components manufactured via selective laser melting. Proc. Inst. Mech. Eng. Part C J. Mech. Eng. Sci. 2020. [CrossRef] 